\title{
Routing Problems in Emergency Logistics Based on Improved Data Envelopment Analysis
}

\author{
X.X. Zhu \\ School of Management, Harbin Institute of Technology \\ P.R. China
}

\author{
S.Y. Wang \\ School of Management, Harbin Institute of Technology \\ P.R. China \\ School of Architecture, Harbin Institute of Technology \\ P.R. China
}

\begin{abstract}
Emergency decision making is still an important issue for unconventional emergency management. For nonstandardized weight distribution in the data envelopment analysis model, an improved data envelopment analysis model by constructing two decision making units, which have the highest and the lowest efficiency to expand the scope of the efficiency value and to avoid the influence of artificial factors on the decision is proposed. Aiming at choices of routing optimization in emergency logistics, this paper also uses multi-objective decisionmaking to solve problems, i.e., time, cost and transportation distance of materials. Finally, the validity of the approach and the applied process of the proposed model are tested by a numerical example with the case of the earthquake emergency in Gansu Province, China.
\end{abstract}

Keywords-the improved data envelopment analysis; multiobjective decision-making; route optimization; emergency logistics

\section{INTRODUCTION}

Natural disasters, accidents, public health, public security and other unexpected incidents frequently occur, and in areas with high population densities, human casualties can be great[1]. Therefore, how to efficiently transport materials in emergency disasters to the demand point becomes a key problem in the disaster relief process. Emergency logistics are special logistics activities to ensure that the demand of materials, personnel, and money are allocated to public health emergencies, major accidents and other emergencies which are sudden, uncertain, unconventional, and with urgency based on time constraints that benefit from a maximum of time management with an objective of minimum disaster losses [2$6]$.

Data envelopment analysis (DEA) has been applied in various areas such as hospital services, education (schools and universities), manufacturing, computers, peripheral firms, information technology investment, banks, and hotels [7-14].

\section{DESCRIPTION OF MATHEMATICAL MODEL}

\section{A. Data envelopment Analysis (DEA)}

Suppose there are $\mathrm{n}$ DMUs, with $\mathrm{k}$ input factors and $\mathrm{m}$ output factors, and let $\mathrm{i}(1 \leq i \leq n)$ denote one of the $\mathrm{n}$ DMUs. The efficiency Ei of the ith DMU, with outputs $Y_{i}=\left(y_{1 i}, y_{2 i}, \ldots, y_{m i}\right)^{T}>0$

and inputs
$X_{i}=\left(x_{1 i}, x_{2 i}, \ldots, x_{k i}\right)^{T}>0, \mathrm{i}=1,2, \ldots, \mathrm{n}$, where $x_{k i}$ is the kth input of the ith DMU, ${ }^{y_{m i}}$ is the mth output of ith DMU, is calculated by the following C2R model:

$$
\begin{array}{ll}
\max \left(\frac{\mu^{T} Y_{i}}{v^{T} X_{i}}\right) & \\
\text { s.t. } \quad & \frac{u^{T} Y_{j}}{v^{T} X_{j}} \leq 1, j=1,2, \ldots, n \\
& u \geq 0, v \geq 0
\end{array}
$$

The above constraints restrict the efficiencies of all the DMUs to have an upper bound of 1 . The ith DMU is efficient when $\mathrm{Ei}$ is equal to 1 and inefficient if $\mathrm{Ei}$ is less than 1. The variables $v=\left(v_{1}, v_{2}, \ldots, v_{k}\right)^{T}$ and $u=\left(u_{1}, u_{2}, \ldots, u_{m}\right)^{T}$ are the derived weights for the corresponding output and input factors. Model (1) is a fractional programming in which $v$ and $u$ have infinite solutions. Subjected to $v^{T} X_{j}=1$ which has efficient solutions, then model (1) is transformed into an equivalent multiplier form of the linear programming model (2):

$$
\begin{gathered}
\begin{cases}\max \mu Y_{j} \\
\text { s.t. } & \frac{u^{\prime} Y_{j}}{v^{\prime} X_{j}} \leq 1, j=1,2, \ldots, n \\
& v^{\prime} X_{j}=1 \\
& u \geq 0, v \geq 0\end{cases} \\
\begin{cases}\min (\theta) & -Y_{i}+Y \lambda \geq 0 \\
\operatorname{s.t.} & \theta X_{i}-X \lambda \geq 0 \\
\lambda \geq 0\end{cases}
\end{gathered}
$$

Linear programming model (2) is transformed into an equivalent binary form, i.e., the basic C2R model of DEA method (3). 
$\theta$ is a scalar which represents the efficiency score of DMUi where $0 \leq \theta \leq 1$. $\lambda$ is a constant vector. The binary form of the linear programming has fewer constraints [18] than the multiplier form which creates problems for the uneven weight distribution of the input and output factors.

\section{B. Improved Data Envelopment Analysis Model}

The specific steps of the improved DEA model are as follows:

Step 1: Construct DMUn+1 and DMUn+2 which have the highest and lowest efficiency,

Step 2: Determine the index weight of the input and output factors.

Evaluate the last $n$ DMUs and DMU which has the highest efficiency by using the improved DEA model. DMUn+1 is the optimal DMU, so when $\mathrm{i}=\mathrm{n}+1, \theta=1$. Then the optimal weights $u *^{T}$ and $v^{* T}$ are obtained, which satisfies $\frac{u^{*^{\prime}} y_{j}}{v^{*^{\prime}} x_{j}}=1$.

Step 3: Solve the common weight vector of the input and output factors.

\section{Establishing the Improved Data Envelopment Model}

\section{1) Illustration}

After a natural disaster, the National Center for Emergency Management informs technical institutions to make route optimization plans for the transportation of goods and services. Suppose there are n plans (n DMUs) to be evaluated as DMUj, $\mathrm{j}=1,2,3,4$. In order to make sure the rescue goods and services arrive quickly after major disasters, "shortest time" is often treated as the objective to choose a plan.

Based on the case of the earthquake in the border region between Min County and Zhang County in Gansu Province, this paper gives an improved solution. We choose the total time, cost and transportation distance of materials as main reference indexes to determine the hierarchical structure of route optimization plans in emergency logistics. Suppose there are $n$ lines to be chosen. Line $i(i=1,2, \ldots, n)$ has two types of indicators which are the positive index xki and negative index ymi. xki representing the rescue time, transportation cost and distance, and the smaller value the better. ymi represents the rescue ability of each plan, and the larger the better. Continue the efficiency evaluation for $n$ lines according to the improved DEA model above. Construct line G (DMU7) which has the highest efficiency and line H (DMU8) which has the lowest efficiency. The input and output factors of line $\mathrm{G}$ are:

$$
X_{7}=\left(x_{1,7}, x_{2,7}, x_{3,7}\right)^{T}, Y_{7}=\left(y_{1,7}\right)^{T}
$$

Set input and output factors of DMU7 which has the highest efficiency the minimum value and the maximum value of the last 6 DMUs respectively, i.e.:

$$
\begin{gathered}
x_{2,7}=\min \left(x_{2,1}, x_{2,2}, \ldots, x_{2,6}\right) \\
x_{3,7}=\min \left(x_{3,1}, x_{3,2}, \ldots, x_{3,6}\right)
\end{gathered}
$$

$$
y_{1,7}=\max \left(y_{1,1}, y_{1,2}, \ldots, y_{1,6}\right)
$$

The input and output factors of DMU8 which have the lowest efficiency are:

$$
X_{8}=\left(x_{1,8}, x_{2,8}, \cdots x_{3,8}\right)^{T} \quad Y_{8}=\left(y_{1,8}\right)^{T}
$$

Set input and output factors of DMU8 which have the lowest efficiency as the maximum value and the minimum value of the last 6 DMUs respectively, i.e.:

$$
\begin{aligned}
x_{1,8} & =\max \left(x_{1,1}, x_{1,2}, \ldots, x_{1,6}\right) \\
x_{2,8} & =\max \left(x_{2,1}, x_{2,2}, \ldots, x_{2,6}\right) \\
x_{3,8} & =\max \left(x_{3,1}, x_{3,2}, \ldots, x_{3,6}\right) \\
y_{1,8} & =\min \left(y_{1,1}, y_{1,2}, \ldots, y_{1,6}\right)
\end{aligned}
$$

Evaluate the original 6 DMUs and the DMU which has the highest efficiency. DMU7 is the optimal decision-making DMU, so $\theta=1$. We get the optimal weights of $u^{* \prime}$ and $v^{* \prime}$ which satisfies $u^{* \prime} y_{j} / v^{* \prime} x_{j}=1$.

For DMUs,

$$
\begin{cases}\min _{8}(\theta) \rightarrow 0 \\ \text { s.t. } \quad-y_{i}+Y \lambda \geq 0 \quad i=1,2, \cdots, 8 \\ & \theta x_{i}-X \lambda \geq 0 \\ & u *^{\prime} y_{j} / v *^{\prime} x_{j}=1 \\ & \left(u *^{\prime \prime}, v *^{\prime \prime}\right) \in\left(u *^{\prime}, v *^{\prime}\right) \\ & \lambda \geq 0\end{cases}
$$

\section{EXAMPLE ANALYSIS}

A 6.6-magnitude earthquake struck Northwest China's Gansu province at 07:45 am on Monday, 22nd of July, 2013. In the middle and late stages of the emergency, some materials in the emergency disaster relief needed to be transported from the emergency supply center to the emergency demand point and the road traffic network diagram is as shown in Figure 1. $\mathrm{S}$ is the supply center and $\mathrm{D}$ is the demand point. $\mathrm{Ni}$ $(i=1,2,3,4,5)$ are the network nodes.

In the middle and later stages of emergency, the best route needs to be determined. There are six lines (from $\mathrm{O}$ to $\mathrm{D}$ ), namely

$\mathrm{A}($ line 1$): \mathrm{O} \rightarrow \mathrm{N} 1 \rightarrow \mathrm{N} 2 \rightarrow \mathrm{N} 5 \rightarrow \mathrm{D} ; \mathrm{B}($ line 2$): \mathrm{O} \rightarrow \mathrm{N} 1 \rightarrow \mathrm{N} 2 \rightarrow \mathrm{N} 5 \rightarrow$ $\mathrm{D} ; \mathrm{C}($ line 3$): \mathrm{O} \rightarrow \mathrm{N} 1 \rightarrow \mathrm{N} 5 \rightarrow \mathrm{D} ; \mathrm{D}$

$($ line 4$): \mathrm{O} \rightarrow \mathrm{N} 1 \rightarrow \mathrm{N} 5 \rightarrow \mathrm{D} ; \mathrm{E}($ line 5$): \mathrm{O} \rightarrow \mathrm{N} 1 \rightarrow \mathrm{N} 4 \rightarrow \mathrm{D} ; \quad$ and $\mathrm{F}($ lint6) $\mathrm{O} \rightarrow \mathrm{N} 6 \rightarrow \mathrm{D}$. On the basis of the investigated information, the network in the middle and late stage of emergency and the main path optimization parameters according to the needs of the model are shown as Figure 1 and Table 1 , respectively. 


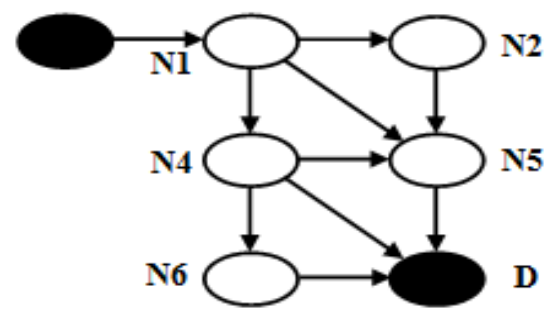

FIGURE I. NETWORK IN THE MIDDLE AND LATE STAGE OF EMERGENCY (ALIGNMENT).

TABLE I . INPUT AND OUTPUT FACTORS OF EACH PLAN (DMU).

\begin{tabular}{cccc}
\hline DMU & time & cost & distance \\
\hline $\begin{array}{c}\text { A } \\
(\mathbf{D M U 1})\end{array}$ & 24 & 60000 & 750 \\
$\begin{array}{c}\mathbf{B} \\
(\mathbf{D M U})\end{array}$ & 26 & 40000 & 890 \\
$\begin{array}{c}\mathbf{C} \\
(\mathbf{D M U 3})\end{array}$ & 18 & 48000 & 480 \\
$\begin{array}{c}\mathbf{D} \\
(\mathbf{D M U})\end{array}$ & 20 & 52000 & 810 \\
$\begin{array}{c}\mathbf{E} \\
(\mathbf{D M U})\end{array}$ & 17 & 70000 & 490 \\
$\mathbf{F}$ & 15 & 84000 & 540 \\
\hline (DMU6) & & &
\end{tabular}

TABLE II . RANKS OBTAINED BY DMUS BY USING DEA AND IMPROVED DEA.

\begin{tabular}{ccccc}
\hline DMUs & DEA & rank & $\begin{array}{c}\text { Improve } \\
\text { d DEA }\end{array}$ & rank \\
\hline A & 0.830 & 4 & 0.667 & 6 \\
B & 1.000 & 1 & 0.833 & 2 \\
C & 1.000 & 1 & 0.800 & 3 \\
D & 0.901 & 2 & 0.722 & 5 \\
E & 1.000 & 1 & 1.000 & 1 \\
F & 0.881 & 3 & 0.778 & 4 \\
\hline
\end{tabular}

From Table 2, the efficiency value using the data envelopment analysis (DEA) model is between 0.830 and 1 which has a difference of 0.170 ; and the efficiency value using the improved data envelopment analysis model is between 0.667 and 1 which has a difference of 0.333 . The greater the efficiency difference expands the scope of the efficiency values which enhances the comparability of DMUs to achieve the goal of effectively distinguishing and sorting DMUs.

From the determined index weight of the two models, we can see there are broader weight constraints in using the DEA model. However, the improved DEA model allows the DMU which has the lowest efficiency to be the least and at the same time guarantees the efficiency value of DMU which has the highest efficiency to be 1 . The different ways that the two models to determine index weight led to different efficiency estimation. In comparison, the index weight of the improved data envelopment analysis model is more canonical and the results of the evaluation are more reasonable and objective.

\section{CONCLUSION}

With the benefits and simplicity of DEA, it has been applied in various areas. However, the DEA model has the problem of non-standardized weight distribution. Route problems of the transportation of materials after an emergency for disaster relief has multiple attributes as the central problem. Decision makers need to develop a balance between time, cost and distance in the middle and later stages of the emergency.

To solve these problems, this paper first points out a defect of DEA which has non-standard weight distribution. Then considering that problem two DMUs which strengthen the weight constraints to achieve the goal of the improved model is constructed. Secondly, the model considers time, cost and transportation distance of materials as the main objectives to evaluate route optimization plans. Finally, the case of the earthquake emergency in Gansu Province shows that the improved data envelopment analysis model is effective, which shows that the method is effective and feasible.

\section{ACKNOWLEDGMENT}

Support for this work was provided by the National Natural Science Foundation (No.71372091)

\section{REFERENCES}

[1] Mooney D D,Swift R J.A course in mathematical modeling[M].The Mathematical Association of America, 1996.234-245.

[2] Xianglong Sun,Jian Lu. A method of emergency logistics route choice based on fuzzy theory[J].Logistics for sustained economic development.ICLEM2010:2816-2822.

[3] Thomas K,Panayiotis M,Katerina P. The impact of replenishment parameters and information sharing on the bullwhip effect: a computational study[J]. Computers \& Operations Research,2008,35(11):3657-3670.

[4] Thanassoulis E.A comparison of regression analysis and data envelopment analysis as alternative methods for performance assessment[J].OplRes.Soc,1993,44(11),1129-1144.

[5] Halme M,Joro T,korhonen P,et al. Value efficiency analysis for incorporating preference information in DEA[J].Management science,2000,45(2):103-115.

[6] Qinjie XIAO, Ruifang MOU.The Application of DEA/AHP in the Natural Disaster Emergency Logistics System[C].Logistics for Sustained Economic Development: ICLEM 2010, 2010:3946-3952.

[7] Jyoti,D.K.Banwet,S.G.Deshmukh. Evaluating performance of national R $\& D$ organizations using integrated DEA-AHP technique[J].International Journal of Proactivity and Performance Management.2008,57(5):370388.

[8] M.Asmild,J.C.Parad,J.T.Pastor. Centralized resource allocation bbc models[J].The international journal of Productivity analysis,2004,22(3):143-161.

[9] Fare R, Grosskopf S. Network DEA[J].Socio-economic planning science,2000,34:35-49.

[10] Yu Dengke, Deng Qunzhao. Several thinking of the DEA method[J].Modern management science, 2012(10):20-24.

[11] Fang Lei.Resource allocation of emergency system based on the DEA model with preference information[J]. Systems engineering theory and practice, 2008,5(5):98-103.

[12] Wang Ting,Yi Shuping,Yang Yuanzhao. Performance evaluation method for business process of machinery manufacturer based on DEA/AHP hybrid model[J].Chinese journal of mechanical engineering,2007, 20(3):91-97.

[13] Yang Min, Wang Wei, Chen Xuewu.Decision-making method for mass rapid transit model selection based on DEA/AHP[J].Journal of highway and transportation research and development.2006,23(7):111-115.

[14] Liu Tianyu, Wang Meiqiang. Evaluation and selection of B2C enterprises to third-part logistics based on B2C enterprises based on DEA-Delphi method[J].Journal of Guizhou University,2013,30(4):136140. 